\title{
Subglottic stenosis following repeated double-lumen tube intubation for whole-lung lavage in a teenager with pulmonary alveolar proteinosis
}

\author{
Christian Seefelder, Christian.Seefelder@childrens.harvard.edu \\ Department of Anesthesiology, Perioperative and Pain Medicine, Children's Hospital Boston, 300 Longwood Avenue, \\ Boston, MA, 02115, USA.
}

\begin{abstract}
Pulmonary alveolar proteinosis is a rare disorder with decreased clearance of surfactant from the pulmonary alveoli resulting in progressive respiratory distress. Whole-lung lavage remains an important procedure for symptomatic relief in patients with pulmonary alveolar proteinosis. If a double-lumen tube can be placed, lavage of one side of the lung is performed through one lumen while the patient is ventilated through the other lumen. We present a patient with pulmonary alveolar proteinosis who, starting at age ten years, underwent multiple intubations with double lumen tubes for alveolar lavage and developed subglottic stenosis which we believe may have been related to the repeated attempts to insert as large as possible a double lumen tube to facilitate lavage. The subglottic stenosis was relieved lastingly following surgical intervention. Subsequently, the smallest double lumen tube which would still appear to be appropriately sized by bronchoscopy and would allow alveolar lavage without spillage was chosen, and dexamethasone was routinely administered around the time of double lumen tube insertion.
\end{abstract}

Keywords: Pulmonary alveolar proteinosis; one-lung ventilation; pediatric anesthesia; subglottic stenosis

\section{Background}

Pulmonary alveolar proteinosis is a rare pulmonary disorder characterized by increasing respiratory distress from accumulation of lipoproteinaceous material in the airspaces of the lung. Absence of functional granulocyte-macrophage colony-stimulating factor (GM-CSF) or inhibition by autoantibodies results in insufficient clearance of the material by macrophages. While treatment approaches utilizing administration of exogenous GM-CSF are being developed, whole-lung lavage to reduce the lipoprotein remains an important mode of symptomatic treatment. This requires the instillation and drainage of large amounts of warmed saline to wash out the sediment. Lung isolation is a prerequisite for this procedure to assure adequate oxygenation and ventilation during the procedure, and double lumen tubes are utilized whenever the patient size allows.

\section{Case report}

Our patient initially presented at nine years of age with cough, fever, and progressive oxygen desaturation. Chest radiograph (CXR) revealed bilateral infiltrates and he was diagnosed with and treated for pneumonia and subsequently for asthma. A few months later he was again diagnosed with pneumonia. Followup CXR showed diffuse interstitial airspace disease bilaterally and a mixed granular reticular pattern. Computed tomography of the chest (CCT) was performed and showed ground glass opacification in all lobes. He underwent bronchoscopy and diagnostic bronchoalveolar lavage which revealed lipid-laden macrophages. Thoracoscopic lung biopsy showed filling of alveolar airspaces with granular eosinophilic material and cholesterol clefts, consistent with pulmonary alveolar proteinosis (PAP). He had a sleep study with desaturation on room air, his electrocardiogram and echocardiogram were negative for cardiac disease.

The patient presented to us for therapeutic whole-lung lavage (WLL) for the first time at age ten years weighing $34 \mathrm{~kg}$. His FVC, FEV1, TLC, FEV1/TLC, DLCO were 64, 68, 73, 93 and $45 \%$ of predicted. He had generalized wheezing, his oxygen saturation was $88 \%$ in room air at rest, $95 \%$ on 3 liters/min by nasal cannula. After induction of anesthesia, a $6.5 \mathrm{~mm}$ inner diameter (6.5 ID) cuffed endotracheal tube (ETT, all single lumen tubes: Mallinckrodt ${ }^{\circledast}$, Covidien Ilc, Mansfield, MA, USA) could not be advanced into the trachea and the patient was intubated with a 6 ID cuffed ETT. This was subsequently changed to a left sided 28 French (Fr) double lumen tube (28 Fr l-DLT) (28 Fr and larger: Mallinckrodt ${ }^{\mathrm{TM}}$ Endobronchial Tube, Covidien Ilc, Mansfield MA, USA). There was difficulty with double lumen tube placement, spillage of lavage fluid during left sided lung lavage, and desaturations. He was extubated at the end of the procedure and recovered in the ICU. He returned for right sided lavage two days later. This time a 28Fr I-DLT did not pass and a $26 \mathrm{Fr}$ I-DLT (Rüsch Bronchopart ${ }^{\circledR}$, Teleflex Medical, Athlone, Ireland) was used. Lavage was completed successfully and the patient was discharged home on post-procedure day one.

The patient returned at age 13 with increasing shortness of breath and decreasing exercise tolerance, requiring oxygen by nasal cannula to maintain oxygen saturation above $90 \%$. Left

(c) 2012 C Seefelder; licensee Herbert Publications Ltd. This is an Open access Article distributed under the terms of Creative Commons Attribution License (http://creativecommons.org/licenses/by/3.0). This permits unrestricted use, distribution, and reproduction in any medium, provided the original work is properly cited. 
C Seefelder. Journal of Anesthesiology and Clinical Science 2012,

http://www.hoajonline.com/journals/pdf/2049-9752-1-4.pdf

doi: 10.7243/2049-9752-1-4

Table 1: Data for the six whole lung lavage procedures and the bronchoscopy with tracheal dilatation. ETT = single lumen cuffed endotracheal tube; ID = inner diameter of ETT in mm; L-DLT = size of left sided double lumen tube in French; BAL = broncho-alveolar lavage.

\begin{tabular}{|c|c|c|c|c|c|c|c|c|}
\hline $\begin{array}{c}\text { age } \\
\text { (years) }\end{array}$ & weight $(\mathrm{kg})$ & bronchoscopy & ETT (ID) & L-DLT & side of BAL & difficulty & postop & comment \\
\hline \multirow[t]{3}{*}{10} & 34 & no & 6.5 & & & unable to pass into trachea & & \\
\hline & & & 6 & & & difficult to advance into trachea & & \\
\hline & & & & $28 \mathrm{~L}$ & left & & extubated to ICU & some spilling \\
\hline \multirow[t]{2}{*}{10} & 34.8 & no & & $28 \mathrm{~L}$ & & unable to pass into trachea & & \\
\hline & & & & $26 \mathrm{~L}$ & right & & extubated to PACU & \\
\hline 13 & 37.3 & no & & $28 \mathrm{~L}$ & left & & extubated to ICU & \\
\hline 13 & 37.3 & no & & $28 \mathrm{~L}$ & right & & extubated to ICU & \\
\hline \multirow[t]{2}{*}{14} & 45 & no & & $28 \mathrm{~L}$ & right & & intubated to ICU & $\begin{array}{l}\text { recommend } 32 \mathrm{DLT} \text { next } \\
\text { time because of spilling }\end{array}$ \\
\hline & & & DLT to 6.5 & & & & & \\
\hline \multirow[t]{3}{*}{14} & 44 & no & 6.5 to DLT & $32 \mathrm{~L}$ & left & & & intubated from ICU \\
\hline & & & DLT to 6.5 & & & unable to pass into trachea & & \\
\hline & & & 6 & & & & intubated to ICU & \\
\hline \multirow[t]{2}{*}{14} & 39.7 & no & & $32 \mathrm{~L}$ & right & unable to pass into trachea & & \\
\hline & & & & $28 \mathrm{~L}$ & & & extubated to PACU & \\
\hline 14 & 42.8 & $\begin{array}{l}\text { subglottic stenosis, } \\
\text { tracheal dilatation }\end{array}$ & & & & & extubated to ICU & \\
\hline \multirow[t]{2}{*}{15} & 47.9 & $\begin{array}{l}\text { minimal subglottic } \\
\text { stenosis }\end{array}$ & & $28 \mathrm{~L}$ & & unable to pass into trachea & & \\
\hline & & & & $26 \mathrm{~L}$ & left & difficult to advance into trachea & extubated to ICU & \\
\hline 15 & 48 & no & & $26 \mathrm{~L}$ & right & difficult to advance into trachea & extubated to ICU & \\
\hline \multirow[t]{2}{*}{$151 / 2$} & $\overline{51}$ & normal & $\mathrm{n} / \mathrm{a}$ & $28 \mathrm{~L}$ & & unable to pass into trachea & & \\
\hline & & & & $26 \mathrm{~L}$ & left & difficult to advance into trachea & extubated to ICU & some spilling \\
\hline $151 / 2$ & 51 & no & & $26 \mathrm{~L}$ & right & & extubated to PACU & \\
\hline 16 & 54 & no & $\mathrm{n} / \mathrm{a}$ & $28 \mathrm{~L}$ & right & & extubated to ICU & \\
\hline 16 & 54 & no & $\mathrm{n} / \mathrm{a}$ & $28 \mathrm{~L}$ & left & difficult to advance into trachea & extubated to ICU & some spilling \\
\hline
\end{tabular}

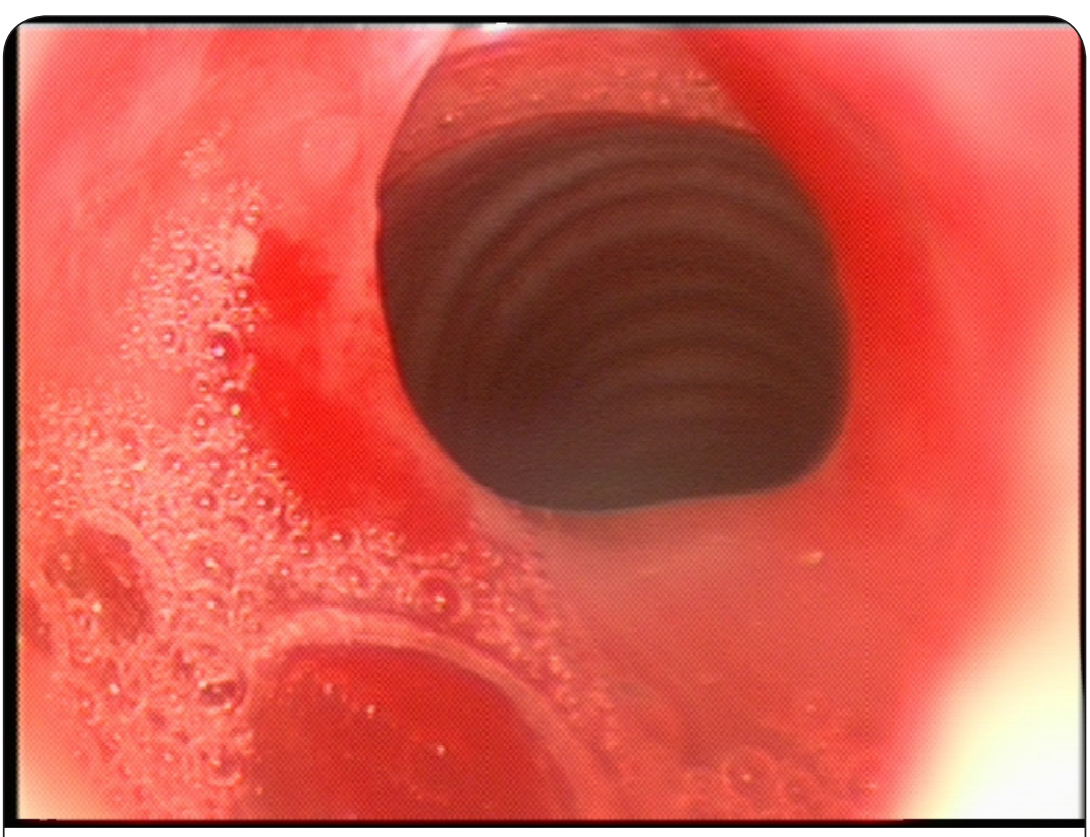

Figure 1: Bronchoscopic view of subglottic stenosis with estimated $40 \%$ obstruction of tracheal lumen. 
C Seefelder. Journal of Anesthesiology and Clinical Science 2012,

http://www.hoajonline.com/journals/pdf/2049-9752-1-4.pdf

and two days later right sided WLL were performed using a $28 \mathrm{Fr}$ I-DLT.

6 months later at age 14, he was symptomatic again and required his next WLL. Lavage of the right lung through a $28 \mathrm{Fr}$ I-DLT resulted in some spillage into the left lung and the session was abbreviated. The DLT was changed to a 6.5 ID cuffed ETT and the patient was ventilated postoperatively. Because of the spillage, a $32 \mathrm{Fr}$ I-DLT was recommended and placed when he returned to the operating room two days later for left sided lavage. He was extubated but required reintubation and a 6.5 ID cuffed ETT could not be passed, thus a 6 ID cuffed ETT was placed. When he returned 4 days later for completion of the right sided lavage, a 32 DLT would not pass and the lavage was performed using a $28 \mathrm{Fr}$ I-DLT. He was extubated at the end of the procedure (Table 1).

The patient returned three weeks later with increasing respiratory distress, increased hoarseness and stridor. Flexible fiberoptic laryngoscopy of his larynx revealed normal supraglottic findings except for some edema but revealed subglottic narrowing. He was subsequently brought to the operating room and a rigid bronchoscopy confirmed a concentric subglottic cicatrix narrowing the airway by about $40 \%$ (Figure 1). Under the same anesthetic, a balloon dilatation of the subglottic narrowing to $12 \mathrm{~mm}$ under a pressure of 3 atmospheres and to $15 \mathrm{~mm}$ under a pressure of 8 atmospheres was performed, resulting in noticeable improvement of the subglottic narrowing. Triamcinolone was injected into the area of the cicatrix and the patient was awakened without problems and with improved air movement.

Since then the patient has undergone three more sessions of WLL. For the subsequent two presentations, he underwent elective rigid bronchoscopy prior to intubation and was found to have a normal subglottis. Double lumen tube insertion continued to be difficult unless the smaller sizes 26 and 28 Fr I-DLT were used, while fiberoptic bronchoscopy to verify position revealed appropriate endobronchial tube size.

\section{Discussion}

Pulmonary alveolar proteinosis (PAP) is a rare pulmonary disorder commonly manifesting in childhood or adolescence with progressive respiratory distress. There is increased accumulation of surfactant or surfactant like lipoproteinaceous material in the lung. The underlying mechanism may be related to decreased clearance of this material through macrophages because of a congenital or secondary deficit of functional granulocyte-macrophage colony-stimulating factor (GM-CSF). Most commonly the etiology is autoimmune with demonstrable levels of antibodies to GM-CSF [1].

Symptomatic relief of respiratory distress and improvement in pulmonary function in PAP can be achieved through wholelung lavage (WLL) to reduce the deposited material. While a single washout may be sufficient for some patients to result in permanent improvement, many patients require multiple sessions of WLL with only temporary improvement. In addition, exogenous GM-CSF administration via inhalation has been shown to be beneficial. In treatment refractory autoimmune PAP, novel treatments with plasmapheresis or use of rituximab may be indicated [1].

If patients are old and large enough, WLL using (typically left sided) double-lumen tubes is the preferred technique: while ventilating one lung through one lumen, the other lumen is used for washout of the material. We typically lavage one side at a time, starting with the worse side by chest radiograph, extubate the patient, recover in the intensive care unit if necessary, and lavage the patient's other side in a second session one or two days later. Sequential lavage of both sides in one session has been reported [2]. Depending on patient size, multiple aliquots of warmed normal saline up to 500 or $1000 \mathrm{ml}$ are infused into and drained from the lung at the time of lavage. We typically use 10-15 liters total, but as much as 50 liters per session have been reported. Positioning changes and chest percussion during the lavage procedure may increase the yield. If tolerated well, lavage is continued until no more deposits form in the collection containers and no further clearance of the retrieved material can be observed (Figure 2).

Spillage of the lavage fluid into the ventilated lung can occur with incomplete lung isolation from an inappropriately sized or suboptimally positioned double lumen tube or from inadequate cuff insufflation, even further complicating oxygenation and ventilation. Instillation typically occurs by gravity infusion. Limiting height for infusion to $50 \mathrm{~cm}$ and instillation volumes to $10 \mathrm{ml} / \mathrm{kg}$ until adequate seal has been demonstrated helps reduce the instillation pressure and minimizes the risk for spillage of lavage fluid past an appropriately placed double lumen endobronchial tube cuff.

In smaller children, whole lung lavage is challenging $[3,4]$. Insertion of two parallel small endotracheal tubes and techniques utilizing balloon tipped catheters (such as pulmonary artery catheter, bronchial blocker, urinary catheter) have been described. The catheter is inserted into the mainstem of the lung scheduled for lavage while ventilation is maintained through the endotracheal tube and via the other mainstem lumen. In very small children, lavage in very small, syringe size aliquots through a bronchoscope inserted via the endotracheal tube and wedged in a distal bronchus, can be used. In severely sick or very small patients, if lung function is severely reduced and/or if lung isolation impossible, lavage while on cardiopulmonary bypass or on extracorporeal membrane oxygenation ECMO may become necessary [5].

In adults, mainstem bronchus size to accommodate the bronchial lumen of a double lumen tube is considered the limiting factor in choosing the double-lumen tube size [6]. Imaging studies show a wide variation of tracheal and bronchial diameters in adults, a gender difference between men and women, as well as a difference of the transverse and antero-posterior diameter. For example Olivier [7] found a left mainstem bronchus diameter range from 8.3 to $19 \mathrm{~mm}$ 


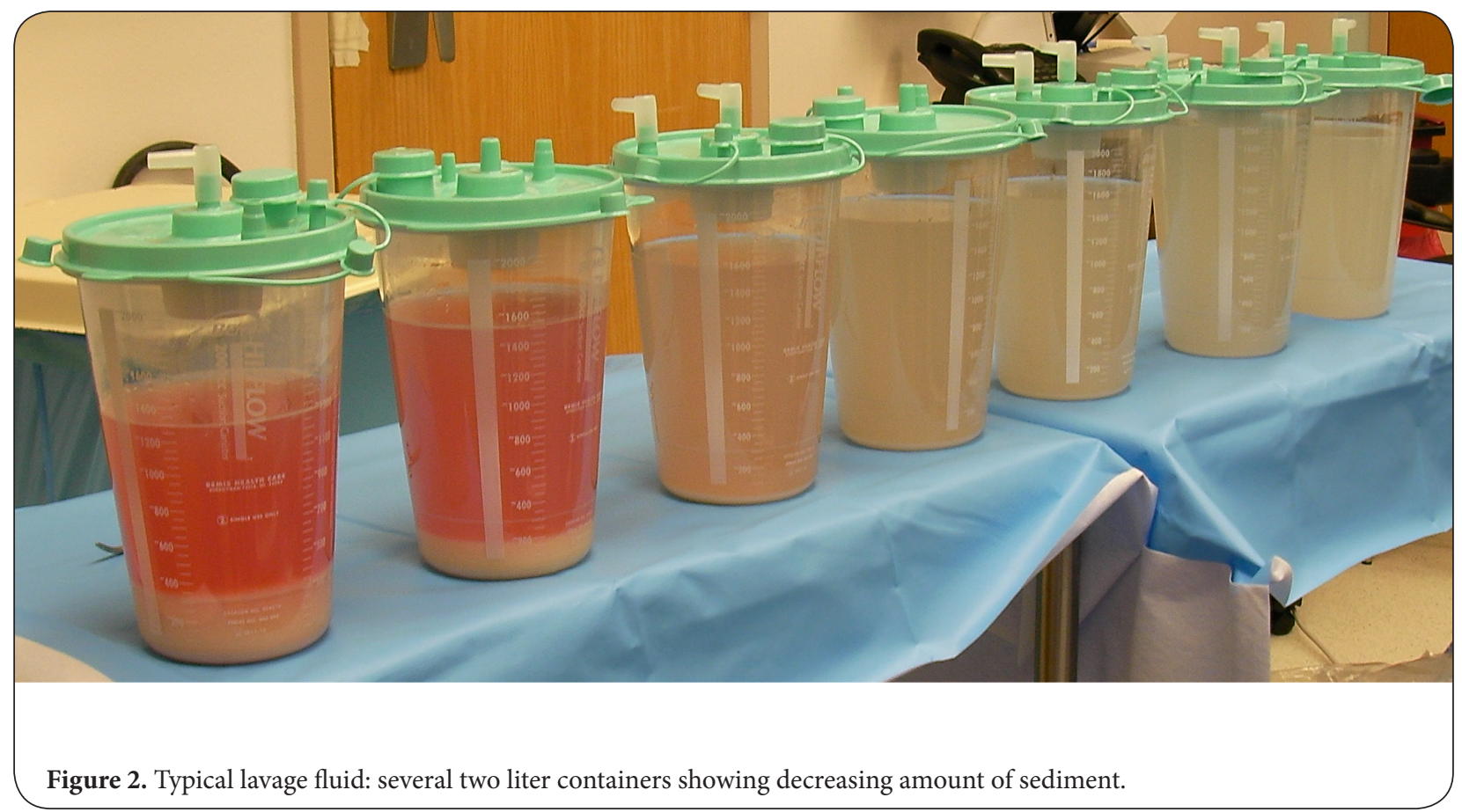

transverse and from 8 to $16 \mathrm{~mm}$ anteroposterior in adult men and measurements of both diameters to decide on doublelumen tube size has been recommended [8]. Investigations found no reliable correlation between bronchial diameter and the more easily measurable tracheal diameter, and measurement of tracheal diameter may not be sufficient to predict bronchus size in adults [9]. However, previously used large double-lumen tubes such as 39 or $41 \mathrm{Fr}$ double-lumen tubes may not be necessary as $35 \mathrm{Fr}$ double-lumen tubes may be sufficient for most adults, did not show any disadvantage and were less likely to need downsizing [10].

Imaging and anatomic studies in children give tracheobronchial dimensions for different ages and recommendations for appropriate endotracheal tube or bronchial blocker size [11]. Anatomic studies in children also demonstrated a difference between antero-posterior and transverse diameters and between different levels of the trachea [12]. Based on such studies, Hammer in his review [13] summarizes size-age relationships for lung isolation techniques in children for one-lung ventilation. Accordingly the smallest (in the US) commercially available 26Fr DLT would be suitable for a ten year old, a 28Fr DLT for a twelve year old, a 32Fr DLT for a fourteen year old, and a 35Fr DLT for a sixteen year old. Surprisingly, double-lumen tube size itself is less predictable than one would assume. Not only are manufacturers' specifications of inner and outer dimensions of their double-lumen tubes not always readily available (for example not published on the package), but actual measurements of the bronchial tube size showed a wide variation in dimensions of the same nominal tube size between different manufacturers and even for each manufacturer itself [14]! The nominal size of a 26Fr DLT would translate into an 8.7 $\mathrm{mm}$ outer diameter without the cuff material. In children not only the bronchial, but also the tracheal diameter especially in the subglottic area may therefore be the limiting factor to double-lumen tube placement. If possible, tracheobronchial dimensions as well as actual double-lumen tube dimensions should therefore be determined before choosing a doublelumen tube in children and teenagers.

Complications from double-lumen tubes range from hoarseness and sore throat [15,16], arytenoid dislocation [17], to life threatening tracheo-bronchial rupture (multiple case reports, for example [18]). Complications may be related to choosing too large a double-lumen tube [19]. Dexamethasone is commonly used to reduce postoperative or postintubation airway swelling and reduces hoarseness after intubation with double-lumen tubes [20].

Subglottic stenosis may be congenital or more commonly acquired. A well-known cause for acquired subglottic stenosis in particular in children is endotracheal intubation from prolonged procedures (such as several hours for WLL) or postoperative ventilation. This may occur at the level of the cricoid ring especially in children where tube size may easily be chosen too large. Subcricoid subglottic stenosis may be related to excessive pressure from an endotracheal tube cuff. There are reports of impossible double-lumen tube placement in patients with congenital subglottic stenosis [21], but we are not aware of reports associating multiple double-lumen tube placements with the development of subglottic stenosis. 
C Seefelder. Journal of Anesthesiology and Clinical Science 2012,

http://www.hoajonline.com/journals/pdf/2049-9752-1-4.pdf

Our patient underwent repeated intubations with doublelumen tubes chosen as large as possible for his age and size in an attempt to allow for optimal lavage. Therefore intubation may have been somewhat forceful from the initial procedure. Although we cannot rule out a preexisting subglottic narrowing in our patient, successful initial placement makes this unlikely. Even though formal measurements of his airway are not available, he may have had tracheal dimensions smaller than average for age resulting in subglottic stenosis formation from the fairly large size double-lumen tubes used.

\section{Conclusion}

In summary, we report a patient with pulmonary alveolar proteinosis who, starting at age ten years, underwent multiple intubations with double-lumen tubes for alveolar lavage and developed subglottic stenosis which we believe may have been related to the repeated attempts to insert as large as possible a double-lumen tube to facilitate lavage. The subglottic stenosis was relieved lastingly following surgical intervention. Subsequently, dexamethasone was routinely administered around the time of double-lumen tube insertion, and we now choose the smallest size double-lumen tube which will allow adequate positioning and sealing confirmed by fiberoptic bronchoscopy (space between the body of the bronchial tube and the wall of the bronchus, adequate seal with minimal insufflation of the bronchial cuff) and will allow single lung ventilation and alveolar lavage without spillage. A $26,28,32$ or $35 \mathrm{Fr}$ DLT is typically selected for patients at a minimum above $10,12,15$, or 18 years and at least above 30 , 40,50 , or $60 \mathrm{~kg}$ respectively. Standard adult DLT size is $32 \mathrm{Fr}$ for females and $35 \mathrm{Fr}$ for males. We rarely see a reason to use larger DLTs at all.

\section{Competing Interest}

The author has no competing interests, financial or otherwise.

\section{Author's Contributions}

The author took care of the patient on several occasions, obtained consent for publication from the patient and legal guardian, and prepared the manuscript.

\section{Acknowledgements and Funding}

Financial support was by institutional sources only.

\section{Publication history}

Editor: Gerald A. Bushman, Childrens Hospital Los Angeles, USA.

Received: 12-May-2012 Revised: 01-June-2012

Accepted: 5-June-2012 Published: 08-June-2012

\section{References}

1. Khan A, Agarwal R: Pulmonary alveolar proteinosis. Respir Care 2011; 56;(7.);1016-28. I Article I PubMed

2. Xie SG, Cai BQ, Zhang H, Liu YJ, Liu T: [Bilateral sequential whole lung lavage in the same treatment session for pulmonary alveolar proteinosis]. Zhonghua Nei Ke Za Zhi 2007; 46;(2.);118-22. I PubMed

3. Reiter K, Schoen C, Griese M, Nicolai T: Whole-lung lavage in infants and children with pulmonary alveolar proteinosis. Paediatr Anaesth 2010; 20;(12.);1118-23. | Article I PubMed

4. Paquet $C$, Karsli $C$ : Technique of lung isolation for whole lung lavage in a child with pulmonary alveolar proteinosis. Anesthesiology 2009; 110;(1.);190-2. I Article I PubMed

5. Lingadevaru H, Romano MA, Fauman K, Cooley E, Annich GM, Cornell TT: Challenges during repeat extracorporeal life support in a patient with pulmonary alveolar proteinosis. ASAIO J 2011; 57;(5.);473-4.. | Article I PubMed

6. Chow MYH, Liam BL, Thng CH, Chong BK: Predicting the size of a double-lumen endobronchial tube using computed tomographic scan measurements of the left main bronchus diameter. Anesth Analg 1999; 88:302-305. | Article

7. Olivier P, Hayon-Sonsino D, Convard JP, Laloe PA, Fischler M: Measurement of left mainstem bronchus using multiplane CT reconstructions and relationship between patient characteristics or tracheal diameters and left bronchial diameters. Chest 2006; 130;(1.);101-7. I Article I PubMed

8. Jeon $\mathrm{Y}$, Ryu HG, Bahk JH, Jung CW, Goo JM: A new technique to determine the size of double-lumen endobronchial tubes by the two perpendicularly measured bronchial diameters. Anaesth Intensive Care 2005; 33;(1.);59-63. | PubMed

9. Hampton T, Armstrong S, Russell WJ: Estimating the diameter of the left main bronchus. Anaesth Intensive Care 2000; 28;(5.);540-2. I PubMed

10. Amar D, Desiderio DP, Heerdt PM, Kolker AC, Zhang H, Thaler HT: Practice patterns in choice of left double-lumen tube size for thoracic surgery. Anesth Analg 2008; 106;(2.);379-83, table of contents. | Article | PubMed

11. Tan GM, Tan-Kendrick AP: Bronchial diameters in children--use of the Fogarty catheter for lung isolation in children. Anaesth Intensive Care 2002; 30;(5.);615-8. I PubMed

12. Butz RO, Jr.: Length and cross-section growth patterns in the human trachea. Pediatrics 1968; 42;(2.);336-41. I PubMed

13. Hammer GB, Fitzmaurice BG, Brodsky JB: Methods for single-lung ventilation in pediatric patients. Anesth Analg 1999; 89;(6.);1426-9. PubMed

14. Russell WJ, Strong TS: Dimensions of double-lumen tracheobronchial tubes. Anaesth Intensive Care 2003; 31;(1.);50-3. I PubMed

15. Knoll H, Ziegeler S, Schreiber JU, Buchinger H, Bialas P, Semyonov K, et al.: Airway injuries after one-lung ventilation: a comparison between double-lumen tube and endobronchial blocker: a randomized, prospective, controlled trial. Anesthesiology 2006; 105;(3.);471-7. I Article I PubMed

16. Zhong T, Wang W, Chen J, Ran L, Story DA: Sore throat or hoarse voice with bronchial blockers or double-lumen tubes for lung isolation: a randomized, prospective trial. Anaesth Intensive Care 2009; 37:441-446. I Article

17. Mikuni I, Suzuki A, Takahata O, Fujita S, Otomo S, Iwasaki H: Arytenoid cartilage dislocation caused by a double-lumen endobronchial tube. $\mathrm{Br} J$ Anaesth 2006; 96;(1.);136-8. I Article I PubMed

18. Kim HK, Jun JH, Lee HS, Choi YR, Chung MH: Left mainstem bronchial rupture during one-lung ventilation with Robertshaw double lumen endobronchial tube -A case report. Korean J Anesthesiol 2010; 59 Suppl;(S21-5. | Article | PubMed Abstract | PubMed Full Text

19. Ambrosio C, Leykin Y, Pellis T, Brodsky JB: Endotracheal kinking of a double-lumen tube: a potential complication of inappropriate size tube selection. Eur J Anaesthesiol 2011; 28;(8.);607-8. I PubMed

20. Park SH, Han SH, Do SH, Kim JW, Rhee KY, Kim JH: Prophylactic dexamethasone decreases the incidence of sore throat and hoarseness after tracheal extubation with a double-lumen endobronchial tube. Anesth Analg 2008; 107;(6.);1814-8. I Article I PubMed

21. Saito $S$, Dohi $S$, Tajima K: Failure of double-lumen endobronchial tube 
C Seefelder. Journal of Anesthesiology and Clinical Science 2012, http://www.hoajonline.com/journals/pdf/2049-9752-1-4.pdf

placement: congenital tracheal stenosis in an adult. Anesthesiology

1987; 66;(1.);83-5. | Article | PubMed

\section{Citation:}

Seefelder C: Subglottic stenosis following repeated double-lumen tube intubation for wholelung lavage in a teenager with pulmonary alveolar proteinosis. journal of Anesthesiology and Clinical Science 2012, 1:4.

http://dx.doi.org/10.7243/2049-9752-1-4 